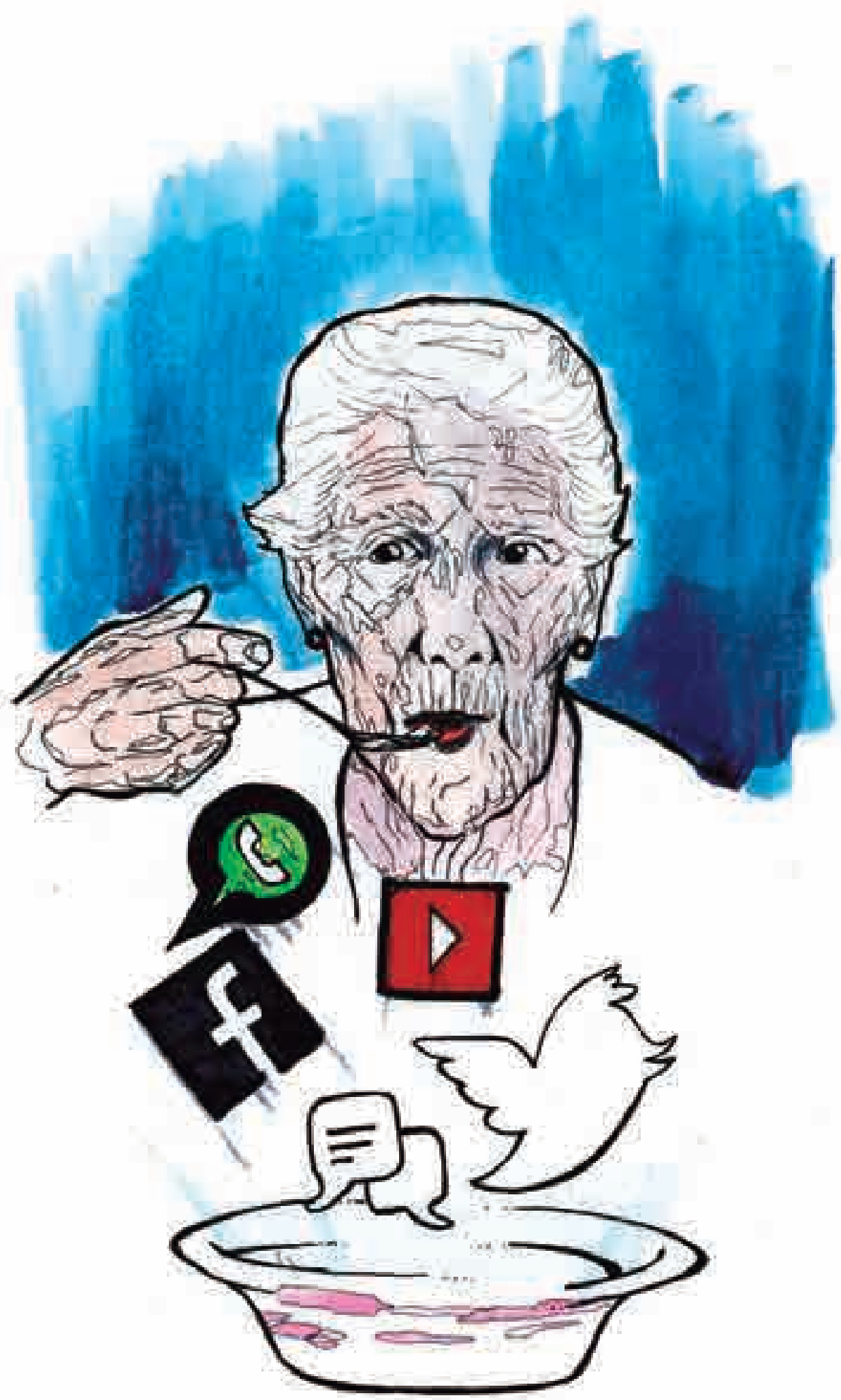

Ilustración 16. Después de las fiestas de Reyes y sin tantas ocupaciones litúrgicas, los frailes se dieron cita en el restaurante 'Sopas de mamá y postres de la abuela', un restaurante típico santafereño. Los tres ordenaron un suculento ajiaco. 


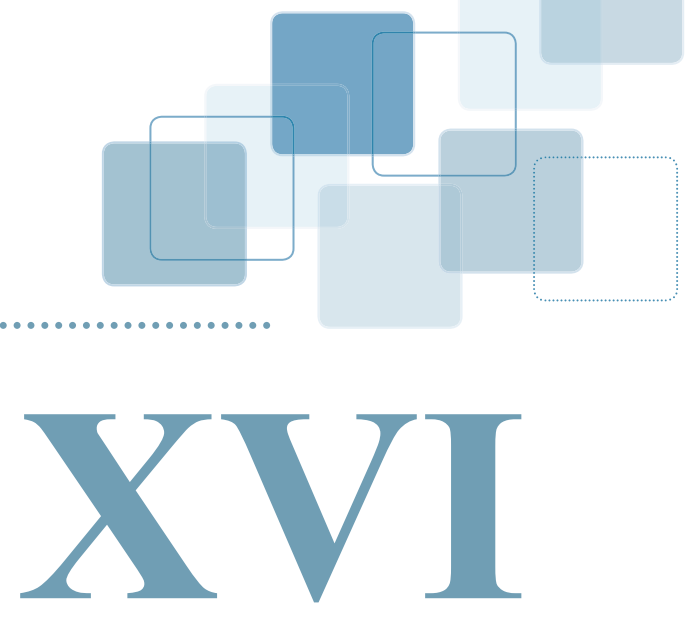

\section{SOPAS DE MAMÁ Y POSTRES DE LA ABUELA}

Después de las fiestas de Reyes y sin tantas ocupaciones litúrgicas, los frailes se dieron cita en el restaurante "Sopas de mamá y postres de la abuela", un restaurante típico santafereño. Los tres ordenaron un suculento ajiaco.

— ¿Cómo les ha ido con el tema de la 'cronotopía' de lo cotidiano? —dijo Carlos Ariel mientras esperaba con ansiedad lo ordenado.

— ¡Bien! he revisado con mucho cuidado los relatos narrativos de los estudiantes y de los padres de familia —señaló Rubén Darío.

-Creo que la palabra 'cronotopía' es un compuesto de dos significados que es mejor separarlos —repuso Luis Eduardo. Sugiero hablar de "cronología de lo cotidiano" y "topología de lo cotidiano".

—De acuerdo —asintió Carlos Ariel.

— ¡Está bien! —dijo Rubén Darío.

- La temporalidad lineal de la historia humana, expresada en el ciclo vital, esto es procreación, concepción, nacimiento, crecimiento, madurez, envejecimiento y muerte, fluye y se destruye en la "cronología 
de lo cotidiano" —afirmó Luis Eduardo. Las narraciones biográficas recogidas dan cuenta del rompimiento inminente del tiempo histórico, que siempre avanza hacia adelante. La temporalidad de la vida cotidiana de nuestros jóvenes parece haberse detenido en el presente. Es como si las manecillas del reloj no vinieran de ningún lugar y no avanzaran hacia ningún otro. Los jóvenes de hoy, como afirma Michel Maffesoli, viven en un 'presentismo', abandonaron todo pasado y todo futuro, para atrincherarse en un instante eterno. La 'amigovia' es la renuncia al amor eterno y la expresión cotidiana de las relaciones amorosas efímeras. El amor como el tiempo de las nuevas generaciones se hizo volátil, líquido y más efímero que nunca. Ello explica porque los jóvenes quieren tragarse la vida de un sorbo y no memorizan, olvidando con extrema rapidez lo que los maestros les enseñan en las aulas de clases —puntualizó.

-El instante eterno que viven nuestros estudiantes es el peor enemigo del recuerdo y el mejor aliado del olvido — repuso Carlos Ariel, mientras atisbaba con agrado la llegada de los ajiacos. Por ello, las tareas, por lo menos en los últimos tres años de educación escolar, no se hacen o peor aún, se realizan al día siguiente antes de empezar las clases. Internet es la metáfora de la disolución de la historia lineal y unívoca de la vida humana -hizo una pequeña pausa, mescló la crema de leche, agregó a las sopas un par de aceitunas y tomó dos cucharadas-. En Vínculos virtuales, Fabián Sanabria afirma: “A partir de nuestro ingreso a Internet algo cambió: adquirimos el tiquete de un viaje sin retorno, hacia un nuevo mundo, ahora no físico sino virtual" (Sanabria, 2011, p. 14). En otras palabras, las banalidades de la vida cotidiana de nuestros jóvenes: el chat, Twitter, Facebook, WhatsApp, Line, YouYube o cualquier hm epage, vitrinear en los centros comerciales, las charlas en los bares y tabernas, las caminatas por la urdimbre callejera, las conversaciones por teléfonos móviles, las relaciones efímeras, los tatuajes, piercings, los viajes en Transmilenio, los calzones descalsurriados, la exteriorización de la ropa interior, entre otros, son expresiones de la fractura del tiempo histórico y la simbolización de un presente divertido, sin ataduras. 
Los jóvenes de hoy ven con desdeño el futuro, mientras que el pasado dejó de importarles para siempre —Finalizó, para comer con agrado el ajiaco.

-La concepción clásica dualista, es decir, pensar el pasado en función del presente, se rompe con la "cronología de lo cotidiano", a través de la cual se desdobla la vida diaria de nuestros estudiantesacuñó Rubén Darío, quien estaba a punto de terminar su almuerzo. Existe de esta manera, una "discontinuidad del tiempo" en la que el presente y el instante, son las nuevas coordenadas de la temporalidad y en los cuales se inscribe el mundo de la vida de los jóvenes que nos fue dado educar. Z. Bauman ya se ha referido a esta "discontinuidad del tiempo", a través de lo que él ha llamado "vida líquida", esta es: "aquella en que las condiciones de actuación cambian antes de que las formas de actuar se consoliden en unos hábitos y en unas rutinas determinadas" (2010, p. 9), en consecuencia, la vida líquida es la metáfora de la temporalidad "presentista" y "efímera". Por eso, los acontecimientos cotidianos de las nuevas generaciones se mueven a gran velocidad: el amor efímero, chatear, conectarse y desconectarse, realizar múltiples actividades al mismo tiempo, el grafiti, visitar las plazoletas de los centros comerciales hoy y mañana, frecuentar el parque o la taberna, jugar Xbox u otros videojuegos por largas horas, son manifestaciones de lo que Bauman ha denominado "nuevos comienzos". Bauman (2010) ofrece otras características de esta vida líquida, cuando afirma:

Las nuevas dietas mejoradas, los aparatos de gimnasia, los cambios del papel pintado de las paredes, el parque donde antes había moqueta (o viceversa), la sustitución de un mini por un todoterreno (o al revés), de una camiseta por una blusa y de una funda de sofá o un vestido monocromático por otra u otro saturado de color, el aumento y la disminución de los pechos, el cambio de calzado deportivo, la adaptación de nuestra marca de licor preferida o de nuestras rutinas diarias a la última moda, y la adopción de un vocabulario novedoso (p. 18).

-Con lo anterior, es fácil suponer que el tiempo cotidiano de las nuevas generaciones no es igual al tiempo cotidiano de sus maestros y 
padres de familia —interpeló Luis Eduardo, quien ya había terminado su comida. En aquellas, el tiempo se hizo líquido, el presente divertido y el instante eterno, en estos, la temporalidad es lineal, viven para tener una larga vida y un futuro asegurado. Las celebridades, ídolos, temas, gustos, novias, videojuegos, valores, el amor, las creencias, atuendos, cortes de cabello, lo bueno y lo malo, entre otros, en los jóvenes son tan volátiles y efímeras a diferencia de las creencias, valores y comportamientos de los adultos, que en oposición a lo líquido, tal vez, deberíamos llamarlos "sólidos". ¿Cómo enseñar cuando el tiempo cotidiano de los sujetos pedagógicos es tan disímil?

-El suelo de la experiencia común diaria, es el espacio de lo cotidiano, que como ya acordamos, vamos a referirnos a él con la expresión "topología de lo cotidiano" - dijo Carlos Ariel. La temporalidad cotidiana se inscribe en el espacio, es decir, la ciudad, el barrio, el estadio, la caja de compensación familiar, la calle, el parque, el cine, el centro comercial, el ciberespacio, el transporte urbano, el afterparty, la taberna, el bar, son estructuras espaciales cotidianas cifradas por la temporalidad cotidiana. En consecuencia, en la "topología de lo cotidiano" el tiempo cotidiano se desdobla. Allí encuentra sentido la vida líquida, el instante eterno, lo efímero y el presentismo alegre y divertido, transgresores de lo rutinario y de lo habitual. Se sale de un sitio para llegar a otro, se vive en un lugar citadino y se abandona temporalmente para visitar la finca, el campo o los restaurantes ubicados a las afueras de la ciudad, se sube a un articulado de Transmilenio para ir a la escuela y se coge otro distinto, para regresar a casa. Se abandona el hogar para ir al centro comercial o a cine o al parque o a comer helado, recreándose así la existencia humana. Sin ello la vida juvenil no tendría sentido.

—La "topología de lo cotidiano" constituye la apropiación del espacio público y privado —afirmó Rubén Darío. El hogar es el lugar para encontrarme con los otros, es decir, los míos, una vez que se sale de él nos perdemos en la infinitud de las calles y arterias urbanas, luego llegamos y nos apropiamos de los espacios "centros comerciales, plazas, estaciones de Transmilenio, parques, restaurantes, 
escuelas, universidades, bares, entre otros", es decir, lo público, lugar de encuentro con los otros, los que no son míos. El espacio urbano empezó a constituirse, según Jacques Le Goff, desde la Edad Media, alrededor de las iglesias y sus campanarios, a través de la conciliación entre un paisaje centrado y un tiempo reinterpretado. Fabián Sanabria ha utilizado la metáfora del "Arca de Noé" para definir el espacio como lugar de encuentro con los otros, porque esta es un "lugar de confluencia o epicentro de todas las especies" (Sanabria, 2011, p. 16). Vale decir, el “Arca de Noé” es la expresión simbólica de la cual se ha valido Sanabria para identificar el espacio cotidiano, como el lugar donde se encuentran y confluyen las diferencias que subsisten entre los seres humanos. Es el lugar donde se construyen relaciones horizontales y fraternas, donde lo distinto tiene cabida y también donde lo absoluto, lo autoritario y la esperanza futura se desvanecen.

-Ahora bien, el término espacio posee una alta condición elástica y abstracta —acuñó Rubén Darío. Espacios de ocio, espacio aéreo, espacio sideral, espacio simbólico, espacio de encuentros, espacio de relajación. En este sentido, aquí entenderemos el espacio, como lo entiende Marc Augé: como acontecimiento "que ha tenido lugar", como mito "lugar dicho", como una historia "elevado lugar" y como una extensión "distancia entre dos cosas o dos puntos" (Augé, 2000, p. 87). De acuerdo con lo anterior, se puede decir que en el espacio cotidiano acontecen diariamente sucesos, estos tienen lugar en sitios emblemáticos de la ciudad. En la ciudad, el barrio, la calle, el centro comercial, se tejen historias cotidianas, se deconstruyen y confluyen otras que se diferencian y distancian de otras que de igual manera se han tejido, construido y deconstruido, en otro lugar de la ciudad, distante del lugar donde he construido mi historia. Las historias cotidianas que se relatan atraviesan muchos lugares, es como el viajero que en su relato describe los sitios que visitó.

-Pero hablar de "espacio", con la razón que tu expresas, Carlos Ariel, este no deja de ser una categoría geométrica —refutó Rubén Darío. 
—¿Qué propones? —dijo Rubén Darío visiblemente molesto.

—iQue hablemos de "lugar" y no de "espacio" —sentenció Luis Eduardo.

—¿Por qué? —interpeló Carlos Ariel.

-Porque el 'espacio' es mudo, frío y no dice nada — Luis Eduardo. "La noción de espacio, tal como es utilizada hoy, parece poder aplicarse útilmente, por el hecho mismo de su falta de caracterización, a las superficies no simbolizadas del planeta" (Augé, 2000, p. 87): la hotelería, instituciones de viaje, espacios de ocio, espacios de juego, entre otros. En cambio, cuando hablamos de 'lugar', de acuerdo con Marc Augé, nos referimos a la "posibilidad de los recorridos que en él se efectúan, los discursos que allí se sostienen y el lenguaje que lo caracteriza", es entender la "topología de lo cotidiano", como un lugar de encuentro con el otro y no como un espacio geométrico diseñado para caminar, vivir o frecuentar simplemente.

—iDe acuerdo! —afirmó Rubén Darío, ante la mirada expectante de sus dos compañeros.

-Ahora bien, hemos identificado a través de los sujetos escolares una gama amplia de lugares, que se hace necesario clasificarlos en contextos más específicos —afirmó Carlos Ariel.

- Creo que 'la ciudad' debe ser uno de esos grandes lugares que acogen a su alrededor otros lugares — sentenció Luis Eduardo.

—iEl Barrio! —gritó suavemente Rubén Darío.

-Sí. Los relatos de los estudiantes y de sus padres, dan cuenta de la importancia del hogar, el conjunto, la heladería, el parque, entre otros. -asintió Carlos Ariel.

— ¿Estoy de acuerdo! —dijo Luis Eduardo. También 'el ciberespacio', representado en los videojuegos, los portales musicales, las redes sociales, el chat, los Inbox, entre otros, es otro de los lugares 
que constituyen la "topología de lo cotidiano" por donde transita la vida de nuestros estudiantes.

-Los hechos narrativos de nuestros estudiantes y sus padres, dan cuenta que 'el centro comercial' es otro lugar cotidiano -interpeló Rubén Darío.

-Sí. Pero yo también agregaría que 'la calle' es un lugar que comunica y sirve de encuentro con los otros. La vida cotidiana transita por las calles, arterias, avenidas, etc., —aseveró Luis Eduardo.

-Entonces, La calle y el centro comercial, serán otro lugar cotidiano - resumió Carlos Ariel. Así tenemos que, la ciudad: el barrio, el ciberespacio, la calle y el centro comercial constituyen los cuatro grandes campos por donde transita la vida juvenil, cada uno de ellos conforman un campo mucho mayor: la ciudad. En estos espacios se traban relaciones, se enamoran y se desenamoran, comen, bailan, gritan, se divierten, hacen travesuras, rompen con la monotonía y con la rutina.

—Ahora bien, ¿cómo traer al currículo y planes de estudios estos lugares? —dijo Rubén Darío.

— ¡Preguntémosle a los maestros! —respondió Luis Eduardo. Todos estuvieron de acuerdo con esta última proposición, Rubén Darío pagó los almuerzos y se despidieron. 
